\title{
Preventive Maintenance of Boiler: A Case of Kuwait Industry
}

\author{
Ahmed S. Kh. R. Q. Alazemi, Mohammad Yeakub Ali and Mohd. Radzi Che Daud
}

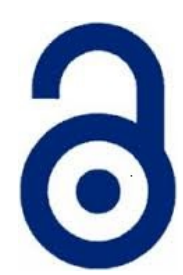

Received: 01 February 2019

Accepted: 20 April 2019

Published: 20 June 2019

Publisher: Deer Hill Publications

(c) 2019 The Author(s)

Creative Commons: CC BY 4.0

\begin{abstract}
In Kuwait, industrial boilers are used extensively in food, chemical, oil and gas, textile, pharmaceutical, power plant sectors for generation steam. As a crucial item in industries, its maintenance is of utmost importance. As there are two main maintenance approaches such as reactive maintenance and preventive maintenance, the application of a typical maintenance is definitely based on types of application, safety concern, and cost benefit ratio. If a boiler is down for few days, it may cause huge loss as it interrupts subsequent steps especially in process industries. In this research, the importance of preventive maintenance strategy for steam boilers in Kuwaiti industries has been studied. Based on relative advantages and disadvantages, a proper strategy is proposed for better management and effective maintenance of boilers.
\end{abstract}

Keywords. Steam boiler, reactive maintenance, preventive maintenance, maintenance strategy.

\section{INTRODUCTION}

A boiler is a steam generating unit. It is a closed metallic vessel contains partly water designed to use the chemical energy in fuel to raise the energy content of water so that it can be used for heating and power applications. Many fossil and non-fossil fuels are fired in boilers, but the most common types of fuel include coal, oil, and natural gas. By heating water above the atmospheric pressure, steam could be generated at the desired pressure and temperature. In brief, the function of a boiler is to evaporate water into steam at constant pressure and to supply the required type of steam (Elie Tawil, 2013).

Industrial boilers are used extensively by food factory, chemical plant, oil field, textile factory, pharmaceutical factory, building material factory, dairy factory, edible fungus factory, garment factory, paper mill, brewery, commercial building, power plant (auxiliary), etc. Commercial and institutional boilers are used in many other applications including commercial businesses, office buildings, apartments, hotels, restaurants, hospitals, schools, museums, government buildings, and airports. Regardless the applications, steam boiler takes into account the safety needs of the actual work, has a variety of comprehensive safety protection functions to maintain $95 \%$ or more efficiency.

Boilers are commonly subdivided into watertube boiler and firetube boiler units. These designations reflect the way the water and combustion gases are designed to pass through the unit. Boilers are also sometimes classified by their heat sources such as oil-fired, gas-fired, coal-fired, or solid fuel-fired boilers. Reliable boiler operation requires a maintenance program that includes inspection, test, and preventive maintenance and repair procedures. For the program to succeed, it must be fully documented and have unequivocal management support. Written procedures for all important activities listed below are to be maintained (Jain, 2012).

- Operations, such as start-up, shutdown, maintenance procedures and abnormal operations,

- Emergency response such as operator response to boiler problems, facility response to boiler problems, and operator and boiler response to facility problems and external challenges,

- Visual inspection and non-destructive testing and evaluation

- Pressure equipment repair and hot work.

A. S. Kh. R. Q. Alazemi, M. Y. Ali $\otimes$ and M. R. C. Daud

Department of Manufacturing and Materials Engineering

International Islamic University Malaysia

PO Box 10, 50728 Kuala Lumpur, Malaysia

E-mail: mmyali@iium.edu.my

Reference: Alazemi, A. S. Kh. R. Q., Ali, M. Y. and Daud, M. R. C. (2019). Preventive Maintenance of Boiler: A Case of Kuwait Industry. International Journal of Engineering Materials and Manufacture, 4(2), 48-52. 
- Ensure both facility employees and contracted personnel are properly trained to comply with facility procedures.

- Conduct periodic refresher training and drills.

- Include all boilers and fired vessels in a central maintenance management system. On each piece of equipment, maintain a file which includes:

\section{LITERATURE REVIEW}

In this section, literature review related to steam boilers is presented. It includes the boiler basics, efficiency, maintenance, and safety. However, the maintenance of steam boiler are reviewed in details, where as other subsections are briefly mentioned. This is because the main thrust of this research is preventive maintenance of industrial steam boilers.

\subsection{Boiler Components}

A number of items must be fitted to steam boiler with the objective to improve operation, efficiency, and safety. However, they are broadly classified in to two, which are (i) boiler mountings and (ii) boiler accessories. A schematic picture of steam generating boiler is shown in Figure 2.1. A general list of boiler mountings and boiler accessories are also presented. Then a brief discussions on boiler mountings (Sadath, 2018) and boiler accessories are presented in the following subsections.

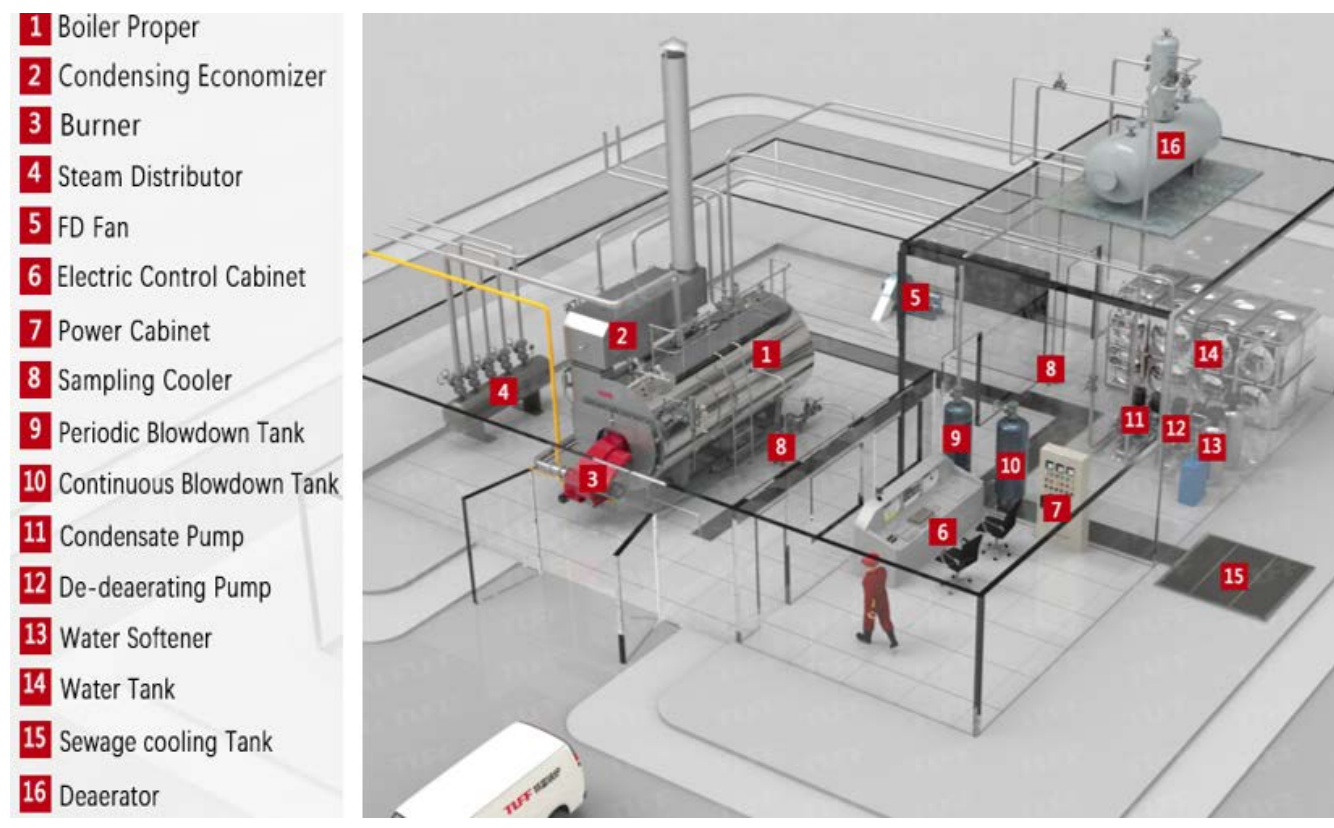

Figure 1: General overview of steam boiler (Watt, 2017)

\subsubsection{Boiler Mountings}

Mountings are crucial, without which the operation of boilers is unsafe. Proper maintenance and care of the mountings is important for the safety of both the boiler and the personnel and to maintain optimum operating condition of the boiler (Sadath, 2018). The boiler mountings are the part of the boiler and are required for proper functioning. In accordance with the Indian Boiler regulations, of the boiler mountings is essential fitting for safe working of a boiler.

1. Safety valves

2. Water level indicators

3. Water level controller

4. Water level alarms \& cut-out assembly

5. Remote water level transmitter

6. Main steam outlet valve

7. Pressure gauge with cock \& Pressure switches

8. Feed water valves

9. Burner assembly

10. Air vent

11. Water sampling valve 
12. Manholes

13. Mud holes \& peepholes

14. Bottom blow down valve

15. De-foaming (scum) valve

16. Furnace drain valve

17. Soot blowers

\subsubsection{Boiler Accessories}

Second categories include the components, which are installed to increase the efficiency of the steam power plants and help in the power working of the boiler unit. These fitting are called boiler accessories. These are also integral part of boiler. Selected boiler accessories are listed below (Boster, 2018).

1. Air pre-heater

2. Economiser

3. Super heater

4. Feed pump and

5. Injector

\subsection{Boiler Efficiency}

The Efficiency of a boiler should be an important part since the annual cost of fuel can easily be 2 to 3 times the installed cost of the equipment. Therefore, a difference in efficiency and the resultant difference in fuel cost can easily offset a difference in capital cost as fuel savings are on going - year after year. The subject of efficiency for a boiler is rather complex when all of the elements that affect efficiency are considered and a complete thermodynamic analysis is performed. The term efficiency is used in the context of a boiler includes boiler efficiency, thermal efficiency, combustion efficiency and fuel-to-steam efficiency (Clayton, 2018). Boiler efficiency has a great influence on heating related energy savings. It requires the maximization of heat transfer to th $3 e$ water and minimization of heat losses in the boiler (R. Saidur, 2010) (Nakkeeran, 2014).

Thermal efficiency refers to the efficiency of a thermal process and mechanical efficiency means the efficiency of a mechanical process. When used in conjunction with boilers, thermal efficiency sometimes refers to the efficiency of the heat exchanger that is fuel-to-steam efficiency. However, fuel-to-steam efficiency is the most significant but is difficult to calculate in real world situations. Therefore, Combustion Efficiency that can be easily computed using a combustion gas analyser is frequently used for performance comparison purposes (Sunit Shah, 2011). Combustion efficiency equals the total heat released in combustion, minus the heat lost in the stack gases, divided by the total heat released. For example, if $100 \mathrm{~kW}$ are released in combustion and $20 \mathrm{~kW}$ are lost in the stack, then the combustion efficiency is $(100-20) / 100=0.80$ or $80 \%$.

Boiler efficiency can be improved by utilizing e economizer, which may give maximum cost benefit. There are two method for testing boiler efficiency (i) direct method and (ii) indirect method. In the direct method, the energy gain of the working fluid (water and steam) is compared with the energy content of the boiler fuel. Whereas in the indirect method, the efficiency is the difference between the losses and the energy input. As such, a detailed maintenance plan should be prepared and implemented. It should include preventive and predictive or proactive maintenance activities. Boiler, air-preheater and economizer tubes are critical parts. Tube cleaning, leak test and wall thickness analysis should be carried out according to maintenance plan. Wall thickness measurement and corrosion check must be carried out for components of flue gas path (Nishadevi Jadeja, 2017).

\subsection{Maintenance Framework}

Maintenance has been defined as the combination of technical and associated administrative actions intended to retain an item or system in, or restore it to, a state in which it can perform its required function (Dhillon, 2002). A proper maintenance needs technical skills, techniques, historical data, methods to properly utilize the assets like factories, power plants, vehicles, equipment and machines. The key objective of maintenance is to ensure system function, life, and safety with minimum cost and expenses. Poorly maintained machines or equipment may lead to random breakdowns causing unavailability for service (Alsyouf, 2007). Three closely related but different decision dimensions are thought to consider simultaneously. These dimensions are (i) output dimension, (ii) risk dimension and (iii) resources dimension. These will be optimising maintenance in an integrated fashion. The overall framework proposed is shown in Figure 2 (Price, 2007).

The bathtub curve, shown in Figure 3, provides a useful mental picture of the likelihood of failure over the life of an asset. Similar to the life of a typical human, there is a greater likelihood of failure (death) at the beginning of life (infant mortality). 


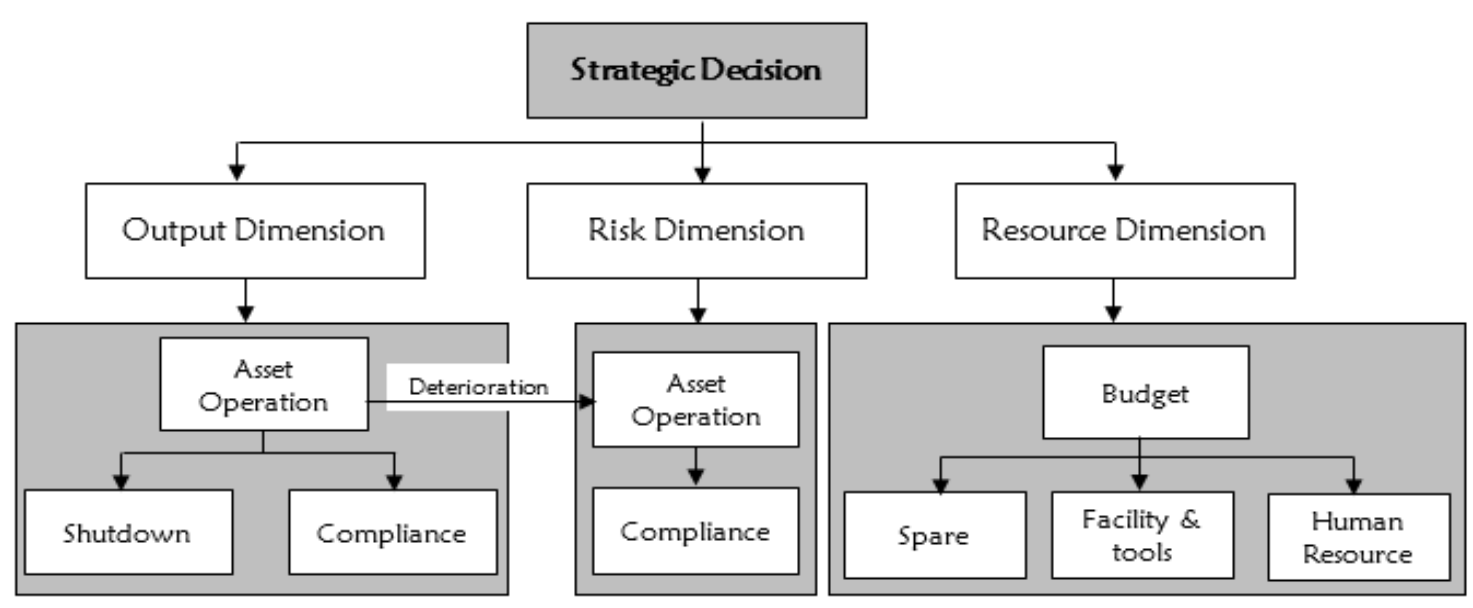

Figure 2: Strategic maintenance framework (Price, 2007)

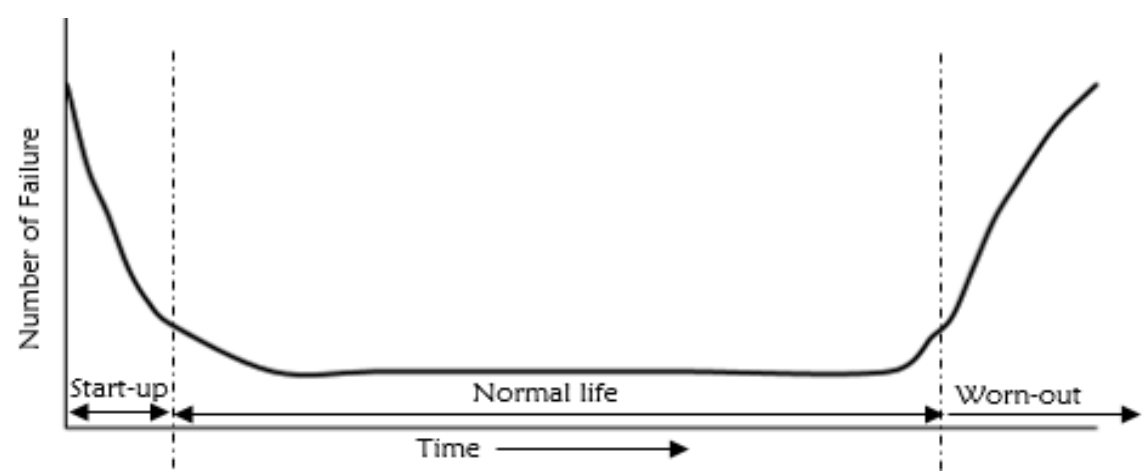

Figure 3: Bathtub curve (FLUKE, 2018) (Daley, 2008)

After the period of infant mortality, the likelihood of failure is relatively low and constant during a long period. As the asset ages, the likelihood of failure increases. While the bathtub curve provides a useful mental model of the likelihood of failure over the life of an asset, it is also somewhat misleading. While life generally takes the form shown on the diagram, it includes the simplifying assumption that we actually have a good idea of when the end of life will occur. That is typically not the case. More frequently, we have a general idea of when the end of life will occur but the manner in which an asset is used will affect when the end of life will occur (Daley, 2008). In the following subsections, reactive and preventive (also called proactive) maintenance strategy are discussed.

\subsubsection{Reactive Maintenance}

Reactive maintenance is the practice of waiting for something to go wrong with the boiler, and then fixing it. While in some ways, this is the simplest strategy that requires no planning or monitoring. It is by no means the most effective maintenance. Taking a reactive approach in boiler maintenance can be quite costly to the business in terms of boiler downtime, parts and labour costs for repairs, and reduced service life for the boiler. Finally, if boiler maintenance relies on reactive approach, it is almost like inviting a problem and the consequences of a boiler problem can be quite severe (Louis, 2018). The likelihood of failure under reactive maintenance is high and frequent over the time as shown in Figure 4 (Daley, 2008).

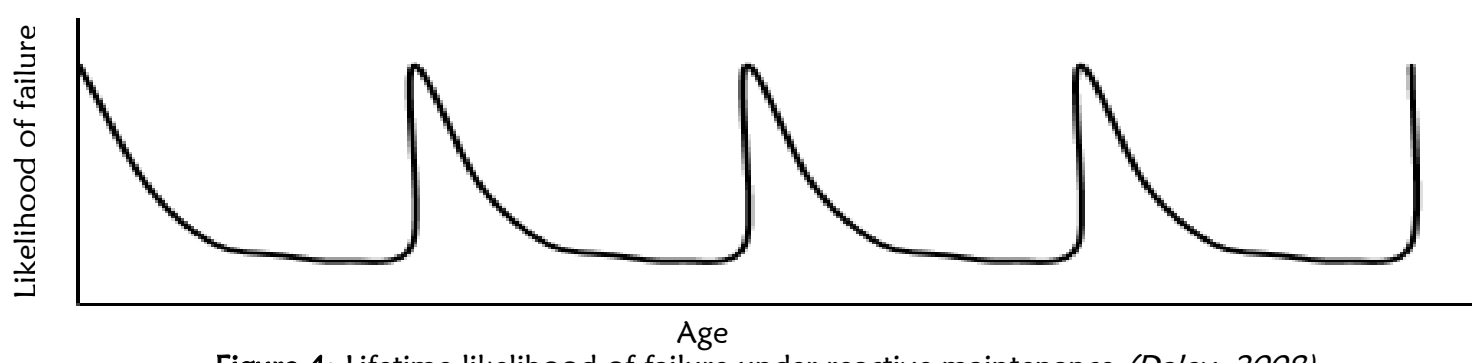

Figure 4: Lifetime likelihood of failure under reactive maintenance (Daley, 2008) 


\subsubsection{Preventive Maintenance}

Efficient operation of boiler can be achieved if preventive maintenance strategy in place. It would be especially beneficial for those plants that rely on breakdown or run-to-failure maintenance. There are many advantages for having a preventive maintenance strategy, which apply to every kind and size of plant. The law of preventive maintenance strategy is that the higher the value of plant assets and equipment (per square foot of plant), the greater will be the return if there is a preventive maintenance strategy.

Preventive maintenance programme consists of actions that improve the condition of system elements for performance optimization and aversion of unintended system failure or collapse. It involves inspection, servicing, repairing or replacing physical components of machineries, plant and equipment by following the prescribed schedule. It is commonly agreed nowadays that preventive maintenance programme can be very successful in improving equipment reliability while minimizing maintenance costs (Sunday Olayinka Oyedepo, 2011). This involves careful watching over the boiler equipment in order to anticipate and correct problems before they have a chance to cause a shutdown or severely affect the performance or service life of the equipment. The foundation of a strong preventive boiler maintenance plan is the historical data. Here are some of the key sectors on which boiler operator collect data on a daily basis (GAPS, 2018):

- Water level

- Operating pressure \& temperature

- Feedwater pressure \& temperature

- Oil pressure \& temperature

- Condensate temperature

- Flue gas temperature

- Fuel consumption

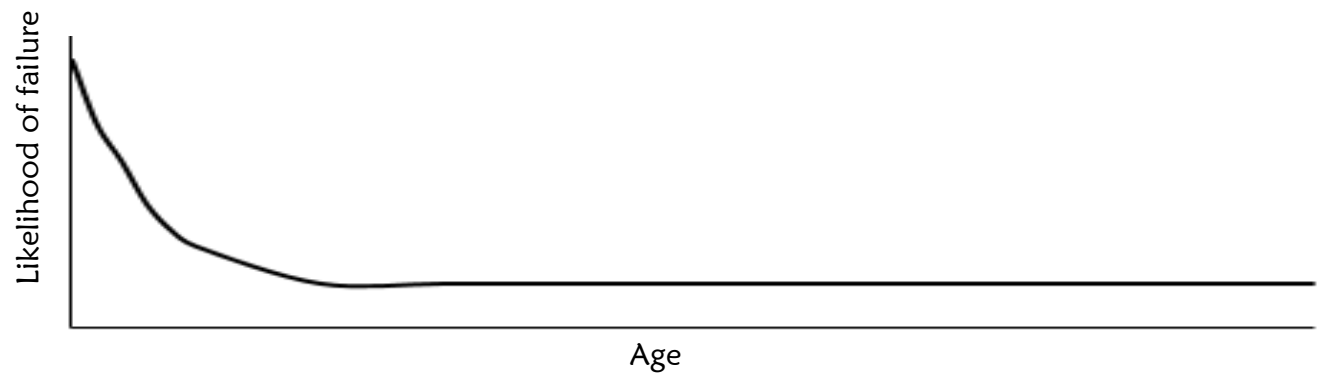

Figure 5: Lifetime likelihood of failure under preventive maintenance (Daley, 2008)

The likelihood of failure under preventive is less and steady over the time as shown in Figure 5 (Daley, 2008). By looking at the data over the course of a week or a month, it is possible to identify changes and trends that could indicate a need for service. This means the operator do not have to wait until the system actually has a serious problem to get service or deal with all the delays and inconveniences associated with such a problem. Routine professional inspections and maintenance visit is another important part of a preventive boiler maintenance strategy. In addition to regular operators, a convenient and planned maintenance services are to be outsourced for few professional visits per year. The conventional professional techniques for non-destructive inspection of boiler materials and parts include liquid penetrant testing, magnetic particle testing, and ultrasonic testing. As such, a preventive maintenance strategy should include the followings (Kiyoshi Shimomura, 2010):

- Non-destructive testing.

- Periodic inspection.

- Pre-planned maintenance activities.

- Maintenance to correct deficiencies found through testing or inspections.

Operating logs for all boiler maintenance are to be strictly maintained. Boiler logs may be as sophisticated as automated digital event recording or as simple as a tag attached to the gauge glass where test activity can be entered. In all cases, provide a written system, which is appropriate to the facility and properly maintained. The system should include, as applicable, records of all safety device tests and inspections, water chemistry activities and critical parameters.

\subsubsection{Preventive Maintenance Schedule}

Preventive maintenance scheduling should be automated to the maximum extent possible. Priority should be given to preventive maintenance and a very aggressive program to monitor the schedule and ensure that the work is completed according to schedule. For Most Boilers: The schedule of preventive maintenance is briefly presented in Table 2.1 as an example (Mobley, 2002). 
Experiences have shown that effective preventive maintenance scheduling can save considerable operational costs while increasing system reliability. In preventive maintenance scheduling, the outages of each unit have to be scheduled in an optimal way satisfying a number of constraints. Over a planning interval, that overall system availability is to be maintained (Hannam, 2007).

Table 1: Schedule of preventive maintenance of steam boiler (Mobley, 2002)

\begin{tabular}{|c|c|}
\hline Frequency & Description \\
\hline Daily & $\begin{array}{l}\text { - } \quad \text { Check water level } \\
\text { - } \quad \text { Check oil level and make note of level (if gas, read gas meter) } \\
\text { - } \quad \text { Chermine daily consumption. } \\
\text { - } \quad \text { Check water temperature and oil pressure gauges for correct readings, } \\
\text { - } \quad \text { Make note of water addition (if any), } \\
\text { - Take reading of stack thermometer, } \\
\text { - Check flame at high fire for length and colour. }\end{array}$ \\
\hline Weekly & $\begin{array}{l}\text { - Test low water safety cut off switch, } \\
\text { - } \quad \text { Do a } 15 \text {-second blow-down on the: Column, } \\
\text { - } \quad \text { Low water automatic water feeder, } \\
\text { - } \quad \text { Surface valve, Oil preheater (for oil burners), } \\
\text { - } \quad \text { Clean strainers and filters (oil burners). }\end{array}$ \\
\hline Monthly & $\begin{array}{l}\text { - Clean spinning cup or nozzle, } \\
\text { - Clean fire eye and smoke detection eye on chimney, } \\
\text { - } \quad \text { Check prerotation veins for any oil residue, } \\
\text { - } \quad \text { Check combustion chamber for any oil residue, } \\
\text { - } \quad \text { Thoroughly clean burner and burner assembly, } \\
\text { - Clean tubes (once a year if oil or gas), } \\
\text { - Test the safety relief valve on the boiler. }\end{array}$ \\
\hline Yearly & $\begin{array}{l}\text { - Have a complete burner overhaul, } \\
\text { - Conduct an efficiency test on the burner, } \\
\text { - } \quad \text { Clean stack and breaching, } \\
\text { - } \quad \text { Have a waterside boil out done, } \\
\text { - } \quad \text { Once every five years: (oil burners), } \\
\text { - Have the oil tank cleaned and inspected, } \\
\text { - Have the oil lines to and from the boiler steam-cleaned. }\end{array}$ \\
\hline
\end{tabular}

\subsubsection{Benefit of Preventive Maintenance}

The most important benefit of a preventive maintenance strategy is reduced costs as seen in many ways by aversion of system failure (Jain, 2012):

1. Reduced production downtime.

2. Better conservation of assets and increased life expectancy of assets, thereby eliminating premature replacement of boiler machinery and equipment.

3. Reduced overtime costs and economical use of maintenance workers due to working on a scheduled basis instead of a crash basis to repair unanticipated breakdowns.

4. Reduced cost of repairs by reducing secondary failures. When parts fail in service, they usually damage other parts.

5. Identification of boiler equipment with excessive maintenance costs, indicating the need for corrective maintenance, operator training, or replacement of obsolete equipment.

6. Improved safety and quality conditions. 


\subsubsection{Preventive Maintenance of Boilers in Kuwaiti Industry}

Although there are many steam generating boilers in Kuwaiti industrial sectors, there are not many article to report that report the maintenance strategy for boilers. It is assumed that the application of preventive maintenance is not precisely practiced.

Failure of steel tubes in a super heater boiler used at one of Kuwait electrical and Power plant has been investigated by Kuwait Institute for Scientific Research and reported. The failure was due to high heat input, which reached up to $700^{\circ} \mathrm{C}$ for long time. At this high heat level, the steel microstructures transformed and caused failure (A. Husaina, 2005). The importance of preventive maintenance was highlighted while investigating the failure of superheated firetube of boiler in Kuwaiti industries. It is recommended that boiler firing should be checked periodically and adjusted to the operation to fit the initial design (M. Alradhi, 2011). Ineffective maintenance and management methods and the lack of timely, factual knowledge of asset condition caused high maintenance cost represent a substantial opportunity for every manufacturing and production facility worldwide. Effective application of preventive/predictive maintenance can reduce 30-50\% (FLUKE, 2018).

\section{PROBLEM STATEMENT}

Steam boilers are unavoidable items in modern industrial civilization. Boilers are extensively used in food factory, chemical plant, oil field, textile factory, pharmaceutical factory, building material factory, dairy factory, garment factory, paper mill, commercial building, power plant, office buildings, apartments, hotels, restaurants, hospitals, schools, museums, airports, etc. Regardless the applications, a comprehensive maintenance and safety protection are to be ensured for safe and efficient functioning of any steam boilers. Although there are several maintenance approach for efficient boiler maintenance and effective functioning, they have their own merits and demerits, which are associated to cost, and benefits. Among the approaches, preventive maintenance of steam boilers is thought to be the best for efficient and smooth functioning.

However, historically it was observed that the steam boilers in Kuwait industrial sectors suffers from sudden malfunctions and causes process interruption and hence financial loss. As such, a critical investigation of application of preventive maintenance of steam boilers in Kuwait industrial sectors is essential. In this research, the application of preventive maintenance of steam boilers is to be surveyed and analysed to identify any weakness and to propose appropriate preventive maintenance of steam boilers in Kuwaiti industries. The cost effectiveness for preventive maintenance is also will be analysed. Based on the present literature review, the research gap has been analysed and presented in Table 3.1.

\section{RESEARCH PHILOSOPHY}

Kuwaiti industrial sectors rely on labour from Kuwaiti citizen as well as foreign experts and workers. Many of the services are subcontracted to local and overseas companies for years. As such, the people at the workplace are from various nationalities, language and cultures. However, most of the companies have no induction programme for harmonization, language and technical training to develop the eco system at workplace. As a result, there are differences in understanding of technical responsibilities and practices. Therefore, it is assumed that either there is no well-designed strategy for preventive maintenance of steam boilers in Kuwaiti industries or the existing strategies could not be strictly followed for safe and efficient running of steam boilers.

\section{RESEARCH SCOPE}

The main scope of this project is to study the practice of preventive maintenance of steam boilers in Kuwaiti industries to identify weaknesses and then propose effective approaches for better maintenance of steam boilers. It includes the followings:

1. Studying and investigating the existing preventive maintenance practices for steam boilers in Kuwaiti industries.

2. Analysis of surveyed data to identify the insufficiency of maintenance approaches for steam boilers in Kuwaiti industries.

3. Propose efficient approaches for preventive maintenance of steam boilers to ensure smooth and efficient running of boilers in Kuwaiti industries.

\section{RESEARCH OBJECTIVES}

The objective of this research is to formulate efficient approaches for effective preventive maintenance of boilers in Kuwaiti industries. The specific objectives of this research are as follows.

1. To study the present preventive maintenance approach and real practice for boilers in Kuwaiti industries.

2. To study the enforcement from the government to comply for maintenance of boilers for efficient and safe running.

3. To analyse the surveyed data to formulate efficient and applicable approaches for preventive maintenance of steam boilers.

4. To validate the proposed strategy for preventive maintenance of steam boiler in one of the selected industries. 
Table 0.1: Research gap analysis based on literature review

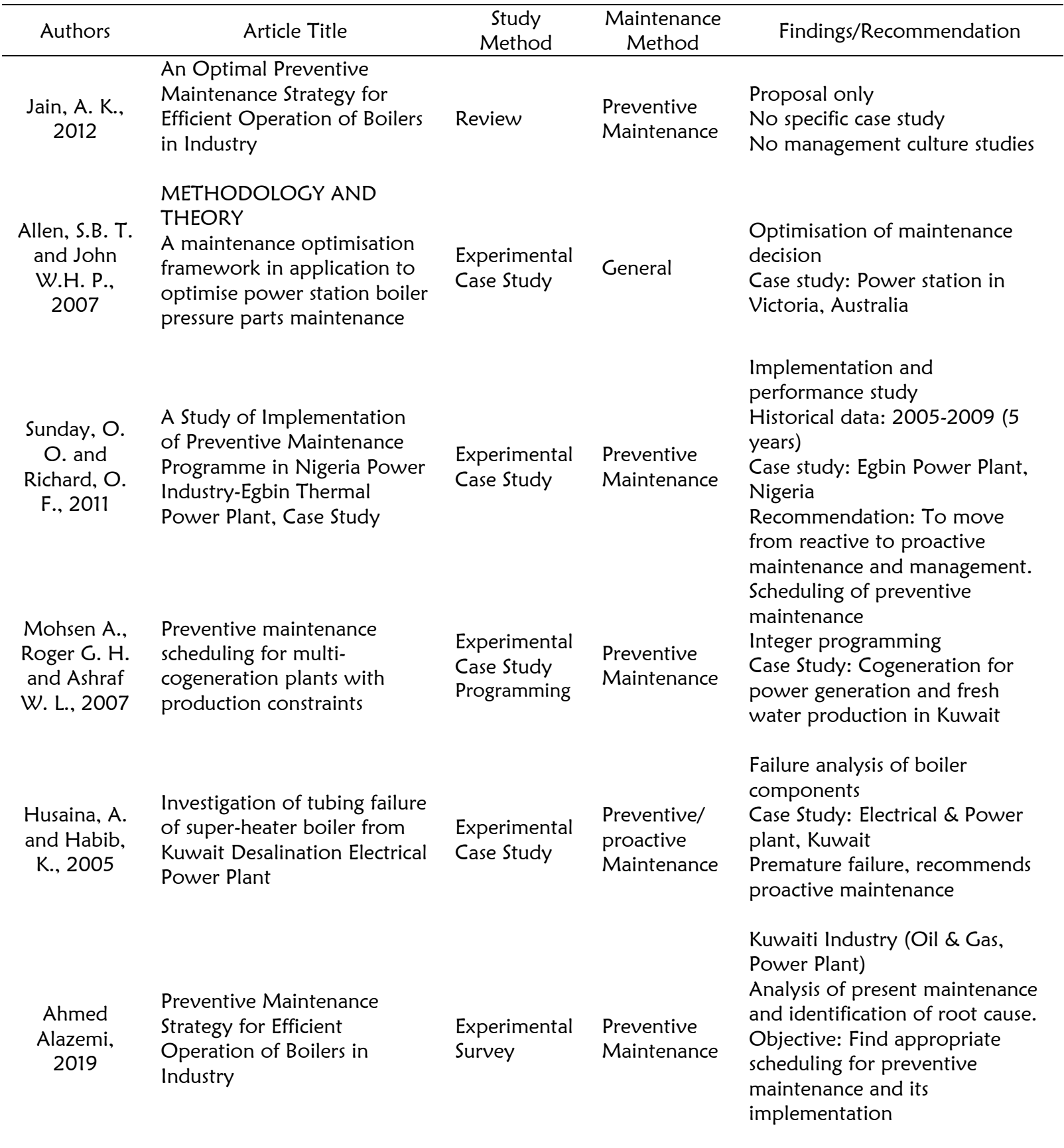

\section{RESEARCH PHILOSOPHY}

Kuwaiti industrial sectors rely on labour from Kuwaiti citizen as well as foreign experts and workers. Many of the services are subcontracted to local and overseas companies for years. As such, the people at the workplace are from various nationalities, language and cultures. However, most of the companies have no induction programme for harmonization, language and technical training to develop the eco system at workplace. As a result, there are differences in understanding of technical responsibilities and practices. Therefore, it is assumed that either there is no well-designed strategy for preventive maintenance of steam boilers in Kuwaiti industries or the existing strategies could not be strictly followed for safe and efficient running of steam boilers. 


\section{RESEARCH SCOPE}

The main scope of this project is to study the practice of preventive maintenance of steam boilers in Kuwaiti industries to identify weaknesses and then propose effective approaches for better maintenance of steam boilers. It includes the followings:

1. Studying and investigating the existing preventive maintenance practices for steam boilers in Kuwaiti industries.

2. Analysis of surveyed data to identify the insufficiency of maintenance approaches for steam boilers in Kuwaiti industries.

3. Propose efficient approaches for preventive maintenance of steam boilers to ensure smooth and efficient running of boilers in Kuwaiti industries.

\section{RESEARCH OBJECTIVES}

The objective of this research is to formulate efficient approaches for effective preventive maintenance of boilers in Kuwaiti industries. The specific objectives of this research are as follows.

1. To study the present preventive maintenance approach and real practice for boilers in Kuwaiti industries.

2. To study the enforcement from the government to comply for maintenance of boilers for efficient and safe running.

3. To analyse the surveyed data to formulate efficient and applicable approaches for preventive maintenance of steam boilers.

4. To validate the proposed strategy for preventive maintenance of steam boiler in one of the selected industries.

\section{RESEARCH METHODOLOGY}

The research initiative starts with literature review of relevant technical and government enforcement papers in the field. Based on state of the arts literature review, problem statement, research objective, and scope are established. Research methodology is developed to carry out the research. Data will be collected from one of the power plant in Kuwait and will be analysed to identify why present method of maintenance is found to be ineffective. Then questionnaire is designed for data collection. Based on data analysis, research findings will be established. At the end, a report will be prepared with empirical relationship and recommendation. The process is depicted in Figure 6.

\section{PRESENT STUDY AND PRELIMINARY RESULT}

Research design and questionnaire have been prepared to collect historical data related to boiler maintenance in Kuwaiti oil and gas sector for further analysis and to find the correlation due to unplanned shutdown of the plant.

The preliminary studies showed that the boiler maintenance and management in Kuwait still esteems tough, individualistic, dominating leadership that often fails to perceive threats or opportunities. Management that is more effective would be pivotal to organizing personnel to recognize pertinent opportunities and achieve worthwhile results rather than generate impasses, stagnation, bureaucracy and interpersonal conflict. The following maintenance problems are frequently encountered in boiler maintenance in Kuwaiti oil, gas and power sectors:

1. Maintenance is not treated seriously at board level, or even by lower level management.

2. Maintenance processes lack a corporate or business culture (e.g. no business plans, ineffective or superficial budgets and unfocused reports).

3. Maintenance technicians and even team leaders lack adequate management and visionary skills.

4. Preoccupation with introducing advanced maintenance methods, while relevant basic maintenance practices are not being implemented.

5. The Kuwaiti industries are still using traditional maintenance planning to compile maintenance schedules for all equipment and plant. These schedules only rarely reach the shop floor. Hence, maintenance schedule ends up without proper and full implementation.

\section{EXPECTED OUTCOMES}

The expected outcomes of the project titled "Preventive Maintenance Strategy for Efficient Operation of Boilers in Industry" are as follows.

1. Enforcement of current procedure for preventive maintenance of industrial boiler in Kuwait.

2. To propose an efficient plan/schedule of preventive maintenance of boiler to avoid unpredicted maintenance and shut down of boilers.

3. Pilot implementation of the schedule preventive boiler maintenance for effective running of boilers in industry. 


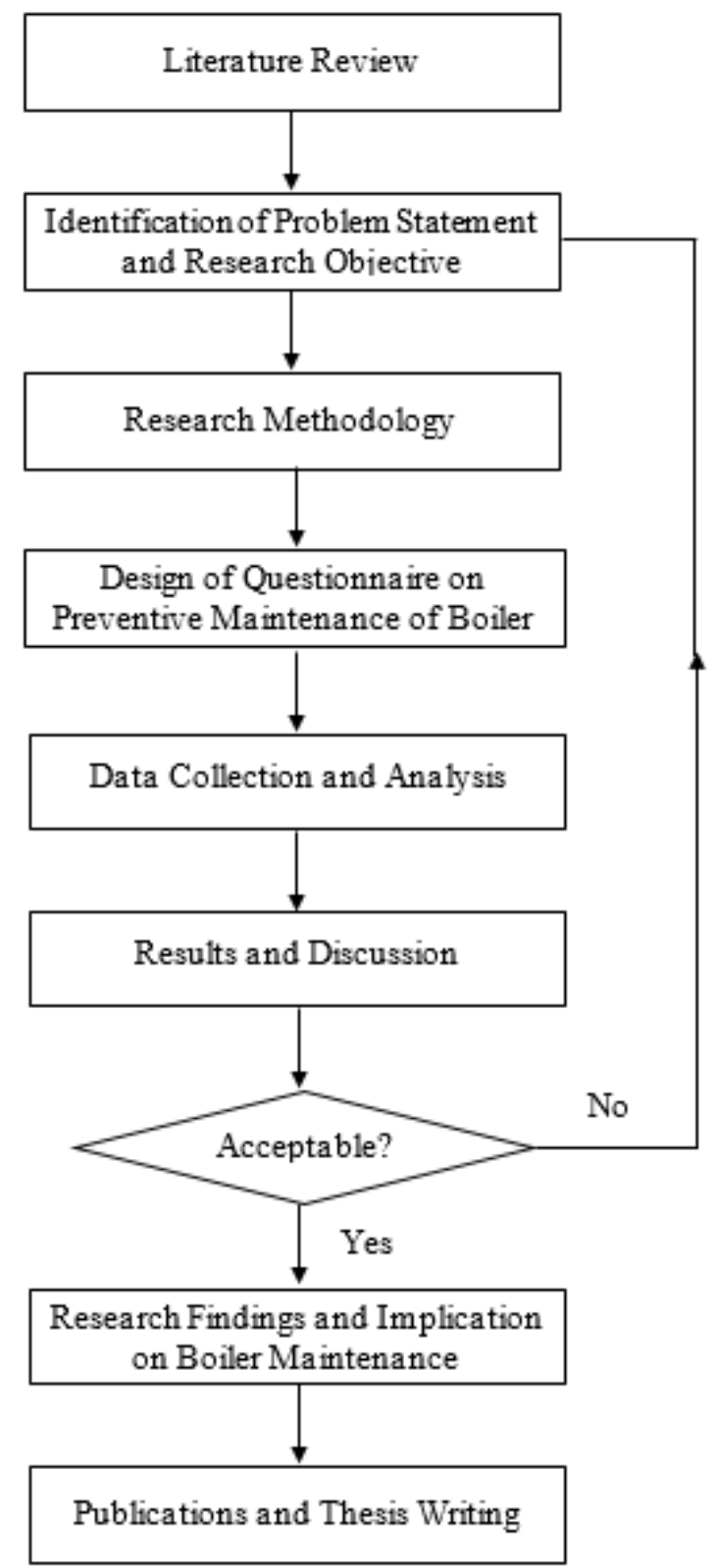

Figure 6: Research methodology

\section{SUMMARY}

This article is based on preliminary study of maintenance of steam boilers in Kuwait industries. The studies are literature review, practical visit and discussion with maintenance personnel. This study showed that:

- The present maintenance systems need to be studied and revised for better services.

- The downtime of boiler should be significantly reduced for efficient and uninterrupted industrial processes.

- Based on the study, selected plant can be considered for pilot study to verify the improvement.

- An appropriate research methodology is proposed for conducting this research.

\section{REFERENCES}

A. Husaina, K. H. (2005). Investigation of tubing failure of super-heater boiler from Kuwait Desalination Electrical Power Plant. Desalination, 203-208.

Alsyouf, I. (2007). The role of maintenance in improving companies' productivity and profitability. International Journal of production economics, 70-78. 
Boster. (2018). Boiler Mountings and Accessories. http://www.mechanicalbooster.com/2016/05/boiler-mountingsand-accessories.html.

Clayton. (2018). Steam Basics-Boiler Efficiency. UK: Clayton Innovative Steam System Solution.

Daley, D. T. (2008). The Little Black Book of Maintenance Excellence. Industrial Press Inc.

Dhillon, B. S. (2002). Engineering maintenance: a modern approach. CRC Press.

Elie Tawil, P. E. (2013). Boiler Classification and Application. Continuing Education and Development. NY, 10980.: Continuing Education and Development, Inc.

FLUKE. (2018). The basics of predictive /preventive maintenance. https://dam-assets.fluke.com/s3fspublic/2534401_b_eng_w.pdf.

GAPS. (2018). Boiler Maintenance and Operation. Global Asset Protection Services LLC.

Hannam, M. A. (2007). Preventive maintenance scheduling for multi-cogeneration plants with production constraints. Journal of Quality in Maintenance Engineering, 276-292.

Jain, A. K. (2012). An Optimal Preventive Maintenance Strategy for Efficient Operation of Boilers in Industry. Control Theory and Informatics, 1-4.

Kiyoshi Shimomura, H. I. (2010). Advanced Technologies of Preventive Maintenance for Thermal Powerplant. Tokyo.

Louis, S. (2018). Is Your Boiler Maintenance Strategy Proactive or Reactive? http://www.stanleylouis.com/is-yourboiler-maintenance-strategy-proactive-or-reactive/.

M. Alradhi, A. A. (2011). Role of Oxide Scale Thickness Measurements in Boiler Conditions Assessment. International Journal of Mechanical, Aerospace, Industrial, Mechatronic and Manufacturing Engineering, 1737-1739.

Mobley, R. K. (2002). An Introduction to Preventive Maintenance. Amsterdam: Butter Worth Heinnman.

Nakkeeran, M. K. (2014). Performance Analysis From The Efficiency Estimation of Coal Fired Boile. International Journal of Advanced Research, 561-574.

Nishadevi Jadeja, S. Z. (2017). Improved Performance of a Industrial Packaged Boiler by Use of Economizer. Improved Performance of a Industrial Packaged Boiler by Use of Economizer, 996-1004.

Price, A. S. (2007). A maintenance optimisation framework in application to optimise power station boiler pressure parts maintenance. Journal of Quality in Maintenance Engineering, 364-384.

R. Saidur, J. U. (2010). Energy, exergyandeconomicanalysisofindustrialboilers. Energy Policy, 2188-2197.

Sadath, O. (2018). Boiler Mountings . Dhaka: https://marinestudy.net/wp-content/uploads/2015/04/BoilerMountings.pdf.

Sunday Olayinka Oyedepo, R. O. (2011). A Study of Implementation of Preventive Maintenance Programme in Nigeria Power Industry- Egbin Thermal Power Plant, Case Study. Energy and Power Engineering, 207-220.

Sunit Shah, D. M. (2011). Boiler Efficiency Analysis Using Direct Method. International conference on Current Trends in Thechnology. IEEE.

Watt, M. (2017). General Overview and components of a boiler. Microwatt Energy, http://en.microwatt.cn/index.php?c=content\&a=show\&id=415. 